Meta

Journal des traducteurs

Translators' Journal

\title{
À propos d'un onéreux devoir du citoyen
}

\section{Robert Dubuc}

Volume 16, numéro 3, septembre 1971

URI : https://id.erudit.org/iderudit/002615ar

DOI : https://doi.org/10.7202/002615ar

Aller au sommaire du numéro

Éditeur(s)

Les Presses de l'Université de Montréal

ISSN

0026-0452 (imprimé)

1492-1421 (numérique)

Découvrir la revue

Citer cet article

Dubuc, R. (1971). À propos d'un onéreux devoir du citoyen. Meta, 16(3),

160-161. https://doi.org/10.7202/002615ar d'utilisation que vous pouvez consulter en ligne.

https://apropos.erudit.org/fr/usagers/politique-dutilisation/ 


\section{PROBLÈMES ET SOLUTIONS}

\section{À PROPOS D'UN ONÉREUX DEVOIR DU CITOYEN}

Probablement à cause de l'influence de l'anglais, le mot taxe connaît au Canada français une fréquence d'utilisation supérieure à celle qu'on retrouve dans le français commun.

On lui donne souvent une valeur générique pour désigner « tout prélèvement fait par l'État pour se financer ». C'est le mot impôt qui a normalement ce sens même si dans le français officiel de l'Hexagone contribution, employé par euphémisme, tend à le supplanter pour des raisons d'ordre psychologique. Dans la langue commune toutefois impôt conserve tous ses droits. Exemple : Contribuable écrasé sous le poids des impôts. Les impôts directs et indirects.

Primitivement l'idée de «taxe » est liée à celle de service rendu. La taxe est fondamentalement un droit payé en retour d'un service reçu, comme l'atteste la définition suivante : «Procédé de répartition des charges publiques proportionnellement aux services rendus; somme établie par ce procédé et que doit payer le bénéficiaire d'une prestation fournie par l'autorité publique ${ }^{1}$. » L'idée de proportionnalité, toutefois, n'est pas essentielle, puisque « au sens large, [le mot taxe désigne] une imposition obligatoire, qui, lorsqu'elle correspond à un service n'est pas proportionnelle à ce service ${ }^{2}$ »

On dit donc très correctement : taxe d'eau, taxe d'enlèvement des ordures. Mais souvent à l'idée de « service rendu » se substitue celle d'objectif à atteindre. La «taxe d'hôpital » n'est pas une «pénalisation» de la maladie, mais plutôt un moyen d'aider à financer, aux dépens surtout des gastronomes, les services hospitaliers. Guinot note ce glissement de sens : «Il semble, écrit-il, qu'actuellement le terme taxe est employé lorsque le produit est affecté à un organe déterminé ou est recueilli dans un but précis ${ }^{3}$. 》

1. Paul Robert, Dictionnaire alphabétique et analogique de la langue française, 6 vol., Paris, Société du Nouveau Littré, 1965, au mot taxe.

2. Ibid.

3. J.-P. Guinot et J. Romeuf, Manuel du chef d'entreprise, Paris, P.U.F., 1960, au mot taxe. 
La taxe est encore caractérisée par son mode de perception. On parle de taxe «lorsque le prélèvement est opéré au moment d'une transaction commerciale et [qu'elle] varie selon le prix de celle-ci ${ }^{4} \gg$. Tel est le cas de la taxe de vente, de la taxe sur l'essence, de la taxe sur les spectacles, de la taxe de luxe (imposée sur les dépenses jugées superflues).

Les taxes sur les dépenses somptuaires constituent une sorte de pénalisation pour les personnes qui peuvent se payer certaines compensations pour remédier à la grisaille de l'existence. Pour le législateur, à tout le moins, la taxe apparaît plutôt comme une sorte d'exigence de la justice distributive.

En résumé, disons que la taxe est un droit versé soit au moment d'une transaction commerciale pour servir une fin particulière, soit en retour d'un service procuré par l'État.

Par rapport au mot impôt, celui de taxe apparaît de sens assez restreint. Nous avons signalé plus haut l'acception générique d'impôt. Il faut y revenir puisque ce terme semble lié aux pouvoirs que possède l'État de prélever, pour se financer et subvenir aux charges publiques, une certaine proportion des ressources des particuliers. Dans cette acception générale, impôt s'applique tout autant aux impôts directs qu'aux impôts indirects.

Ces derniers recouvrent sensiblement la notion de taxe que nous venons de préciser. En effet les impôts indirects sont «perçus à l'occasion d'un fait, d'un acte ou d'un échange, [et ne comportent pas] l'établissement de rôles nominatifs ${ }^{5} \gg$.

Nous touchons ici à la distinction fondamentale entre l'impôt indirect et l'impôt direct, ce dernier étant perçu par voie de rôle. C'est pourquoi il n'est pas exact de parler de «taxes scolaires et municipales». Ces contributions sont perçues par voie de rôle et s'assimilent aux impôts directs. On devrait donc dire : «Le maire s'oppose à l'augmentation des impôts fonciers» plutôt que « de la taxe foncière. » «Les impôts scolaires ne permettent plus le financement des écoles locales. »

En conclusion, quand il s'agit du mode de financement d'un gouvernement, qu'il soit scolaire, municipal ou provincial, c'est au mot impôt qu'on doit généralement songer, plutôt qu'à taxe dont le sens en français est trop restreint pour servir à un usage aussi général. On retiendra aussi l'identité établie entre impôt indirect et taxe qui nous permet d'arriver, par ricochet, à la distinction essentielle entre impôt et taxe qui tient au mode de perception : l'impôt indirect étant perçu au moment d'une transaction, l'impôt direct par voie de rôle.

Le seul malheur c'est qu'une telle précision sémantique ne rend pas moins douloureux les déboursés qu'entraîne le financement de l'État à même nos goussets.

RoBert DUBUC

4. J.-P. Guinot et J. Romeuf, Manuel du chef d'entreprise.

5. Henri Barbier, dans Manuel du chef d'entreprise, p. 560. 